\title{
Capital Social, Capital Físico e a Vulnerabilidade do Sertanejo: o Caso das Comunidades de Lustal e Sítio Lagoa no Município de Taua, Ceará
}

Fernando Daniel de Oliveira Mayorga ${ }^{1}$, Ahmad Saeed Khan², Ruben Dario Mayorga*, Patrícia Verônica P. Sales Lima**

Resumo: O município de Tauá está localizado no Sertão do Inhamuns, no Estado do Ceará, uma das regiões mais atingidas pelos impactos das secas periódicas, com suas seqüelas sobre a produção e conseqüentemente sobre a qualidade de vida do sertanejo. Empiricamente observa-se que, durante as crises climáticas, as comunidades têm limitados mecanismos de defesa. Supõe-se que o capital social, como mecanismo aglutinador e facilitador de ações coordenadas, fortaleça as comunidades e diminua a vulnerabilidade. No presente estudo pretende-se verificar e analisar a importância do capital social e o capital físico na estratégia de convivência das comunidades de Lustal e Sítio Lagoa com as estiagens. Para alcançar esta finalidade, elaborou-se um questionário, contendo uma lista de variáveis, considerando capital social, e solicitou-se sua ponderação por especialistas na área. Desta lista selecionaram-se as dez variáveis com maior freqüência. A seguir, na sede do município de Tauá, solicitou-se a colaboração de técnicos e agentes rurais com reconhecida experiência das comunidades e solicitou-se a ponderação das variáveis, incluindo as variáveis mais representativas de capital

\footnotetext{
${ }^{1}$ Fernando Daniel Mayorga: MS em Economia Rural pela Universidade Federal do Ceará. E-mail: fdmayorga@hotmail.com

${ }^{2}$ Ahmad Saeed Khan:Engenheiro Agrônomo, PhD.Prof. Titular do Dep. de Economia Agrícola da Universidade Federal do ceará. E-mail: saeed@ufc.br

*Ruben Dario Mayorga: Economista, PhD. Prof. Adjunto do Dep. de Economia Agrícola da Universidade Federal do Ceará. E-mail: dario@ufc.br

**Patrícia Verônica P. Sales Lima: Engenheira Agrônoma, Dra. Prof. Adjunta do Dep. de Economia Agrícola da Universidade do Ceará. E-mail: pvpslima@ufc.br
} 
Capital Social, Capital Físico e a Vulnerabilidade do Sertanejo: o Caso das Comunidades de Lustal e Sítio Lagoa no Município de Taua, Ceará

físico. Com estas informações, criou-se um Índice na tentativa de mostrar a importância do capital social na redução da vulnerabilidade, assim como a importância relativa do capital social e do capital físico nas comunidades pesquisadas. O presente trabalho permitiu constatar a relevância do capital social e do capital físico como elementos decisivos do nível de vulnerabilidade das comunidades de Lustal e Sítio Lagoa.

Palavras Chave: Capital Social, Capital Físico, Vulnerabilidade, Município de Tauá.

\section{Social Capital, Physical Capital and Vulnerability of Rural Workers: The Case of the Communities of Lustal and Sitio Lagoa in the County of Taua, Ceará}

SUMMARY: The County of Taua is located in the region of Inhamuns in the State of Ceará, one of the areas most affected by impacts of periodic droughts, with their adverse influence on production and consequently on the farmers' quality of life. It is observed that, during climate crises, the communities have limiting defense mechanisms. It is supposed that the social capital, as a mechanism that agglutinates and facilitates coordinated actions, strengthens the communities and reduces the vulnerability.

This study intends to verify and analyze the importance of social and physical capital as a strategy of Lustal and Sitio Lagoa communities to live with droughts. For this purpose, a questionnaire containing a list of social capital variables was submitted to specialists to rank them. Out of this list the ten most frequent variables were selected. Following, in the Taua County, technical specialists and rural agents experienced in these communities were asked to provide weight to social and physical capital variables. With this information, an Index was developed to show the importance of social capital in the reduction of vulnerability as well as the relative importance of social and physical capital in these communities. The present work enabled the verification of the relevance of social and physical capital as decisive elements of the level of vulnerability of the communities of Lustal and Sitio Lagoa. 
Key Words: Social capital, Physical Capital, Vulnerability, County of Tauá.

\section{1 - Introdução}

A cidadania representa algo mais que a sobrevivência. Ela envolve, entre outras coisas, direito à moradia, alimentação, educação, saúde, renda, segurança e lazer. É papel do Estado garantir à população acesso a todas as necessidades básicas, até porque não se pode esperar que alguém com fome e sem moradia tenha estímulo e disposição para estudar e trabalhar. Porém, cinqüenta milhões de brasileiros estão em estado de indigência. No sertão nordestino, a renda per capita do lavrador não passa de $\mathrm{R} \$ 17,00$ mensais.

No Estado do Ceará, quando, por causa das estiagens os reservatórios secam, o Governo passa a assistir a comunidade com água por meio dos carros-pipa. As estiagens são cíclicas e se alternam com períodos "normais". Estudos anteriores têm mostrado historicamente que a vulnerabilidade do sertanejo está diretamente relacionada a estiagens prolongadas (FUNCEME, 1998). As chuvas no Ceará são espacial e temporalmente mal distribuídas, daí a relevância de informações e previsões aprimoradas que possibilitem decisões acertadas por parte dos agricultores. O Sertão dos Inhamuns, onde está localizado o município de Tauá, é uma das regiões mais atingidas pelos impactos das secas periódicas, com suas seqüelas sobre a produção e conseqüentemente sobre a qualidade de vida do sertanejo.

Enquanto é da maior importância continuar melhorando a capacidade de obtenção de informações sobre a previsão das variações climáticas, é igualmente relevante disponibilizar, de forma compreensível para os agricultores, tais informações, na busca de que a maioria deles possa fazer ajustes em suas atividades tornando-os menos vulneráveis aos eventos climáticos. Tem-se constatado, nos diversos municípios do Estado do Ceará e particularmente no município de Tauá, grandes diferenças na magnitude da pobreza - e conseqüentemente de vulnerabilidade - entre as comunidades. Existem características da estrutura física e social que não têm sido suficientemente pesquisadas para compreender a importância relativa de variáveis de capital físico e capital social que determinam essas diferenças. Espera-se que as comunidades com maiores índi- 
Capital Social, Capital Físico e a Vulnerabilidade do Sertanejo: o Caso das Comunidades de Lustal e Sítio Lagoa no Município de Taua, Ceará

ces de capital social e melhor dotadas de capital físico se mostrem mais desenvolvidas e, portanto, menos vulneráveis a mudanças climáticas.

Pouco se conhece sobre a potencialidade do capital social como alavanca essencial para o desenvolvimento comunitário, ou seja, ignora-se o papel do capital social nas comunidades e o valor das instituições públicas e privadas que permitem ações cooperativas capazes de fortalecer a comunidade, assim como também sabe-se pouco sobre a importância do capital social como elemento intangível e permeável nas organizações sociais, que serve como mecanismo aglutinador e facilitador de ações coordenadas que permitem valorizar a comunidade, seu ambiente de atuação, fortalecem a sua participação em associações cívicas, melhoram o ambiente de confiança entre os membros da comunidade e viabilizam sua conversão para empreendimentos inovadores. O presente trabalho se propõe a verificar de que maneira o capital social e o capital físico influenciam o grau de vulnerabilidade das comunidades de Lustal e Sitio Lagoa, principalmente durante períodos de crise climática.

\section{1 - Objetivos}

O objetivo geral do presente trabalho é verificar e analisar a importância do capital social e do capital físico na estratégia de luta das comunidades contra a vulnerabilidade devida a eventos climáticos como as estiagens.

Especificamente pretende-se: a) determinar e analisar os fatores e estratégias essenciais para diminuir a vulnerabilidade do homem do campo nas comunidades de Lustal e Sítio Lagoa às variações climáticas; b) determinar e analisar de que forma a organização social com base na existência de variáveis relativas à formação de capital social, tais como confiança, solidariedade, interação, cooperação e normas sociais, contribuem para o desenvolvimento das comunidades de Lustal e Sítio Lagoa.

\section{2 - Modelo Conceitual}

\section{1- Vulnerabilidade}

A seca tem como conseqüência reduções na produtividade agrícola, diminuição do rebanho, diminuição no nível de água dos reservatórios 
e açudes, assim como escassez de água para o consumo humano. Depois de analisadas as conseqüências físicas, são traçadas as conseqüências sociais como: falta de alimentos, doenças, venda de recursos e bens, principalmente por parte dos pequenos agricultores, e migração para cidades visando encontrar uma melhor condição de vida.

Segundo o Painel Intergovernamental sobre Mudanças Climáticas IPCC apud KELLY e ADGER (2000), vulnerabilidade pode ser definida como a situação em que mudanças climáticas possam destruir ou prejudicar um sistema e depende, não somente da sensibilidade do sistema, mas, também, de sua habilidade para se adaptar às novas condições climáticas. Segundo BOLE et al (1994) os indivíduos, grupos, classes e regiões mais vulneráveis são aqueles que se encontram com um considerável nível de exposição a perturbações, possuindo limitada capacidade de mitigação, sofrendo mais com os impactos causados por crises socioeconômicas ou ambientais e, finalmente, com reduzida capacidade de recuperação após as crises. Neste estudo, portanto, o termo vulnerabilidade representa as estratégias institucionais e da população sertaneja para fazer frente às secas periódicas e à conseqüente diminuição da disponibilidade de água e de alimentos.

\section{2 - Capital Social}

Nos últimos anos tem aumentado o interesse dos cientistas sociais no estudo da variável capital social, assim como vários fatores relacionados como a confiança entre os indivíduos, associativismo e as redes de relações sociais.

No presente estudo dar-se-á destaque ao conceito de capital social, considerado por muitos estudiosos variável importante para o desenvolvimento econômico (FUKUYAMA, 1999) e ingrediente fundamental para se ter um bom governo (PUTNAM, 2000), educação de qualidade (COLEMAN, 1988), assim como saúde de qualidade (CATTELL, 2001), sendo indispensável para a construção de uma sociedade sustentável (JARA, 1999).

GRANOVETTER (1985) e COLEMAN (op. cit.) defendem um meio termo onde os indivíduos encontram-se inseridos numa rede de relações sociais - social networks - onde as pessoas têm seu comportamento defi- 
Capital Social, Capital Físico e a Vulnerabilidade do Sertanejo: o Caso das Comunidades de Lustal e Sítio Lagoa no Município de Taua, Ceará

nido dentro de uma malha de conexões com outros atores sociais. (MONASTÉRIO, 1999). A definição que utilizaremos é a definição dada por PUTNAM (op. cit. p.177), onde ele define capital social como sendo “(...) características da organização social, como confiança, normas e sistemas, que contribuem para aumentar a eficiência da sociedade, facilitando as ações coordenadas”. FUKUYAMA $(1995,1999)$ segue de perto a linha de Putnam e define capital social como uma maneira, com base em normas informais, de promover a cooperação entre dois ou mais indivíduos. GROOTAERT apud JARA (1999) define capital social como o aglutinante que junta a sociedade. Para o BANCO MUNDIAL, a quantidade, qualidade e persistência das interações sociais entre vizinhos, amigos e membros, assim como a habilidade do trabalho em conjunto procurando o bem comum, gera capital social. O capital social é especialmente importante para o pobre já que pode ser usado como substituto do capital humano e do capital físico (WORLD BANK, http://worldbank.org).

Outro aspecto importante citado por COLEMAN (op. cit.) é a característica de bem público do capital social. "Por ser um atributo da estrutura social em que se insere o indivíduo, o capital social não é propriedade particular de nenhuma das pessoas que dele se beneficiam. Assim como todos os bens públicos, o capital social costuma ser insuficientemente valorizado e suprido pelos agentes privados” (PUTNAM, op. cit., p.180).

Segundo FOX (op. cit.) um ambiente positivo seria a primeira coluna de sustentação para estimular a acumulação do capital social. A segunda coluna seria o papel dos atores sociais contribuindo com idéias e motivações para criação do capital social. FOX (op. cit.) concorda com Putnam ao afirmar que o legado histórico de um povo é importante, mas discorda da afirmação que o legado histórico é um fator determinante na criação do capital social. A terceira e última coluna de sustentação seria a possibilidade de interação e integração entre as diversas organizações existentes, principalmente em comunidades que se encontram isoladas geograficamente. BROWN e ASHMAN (1996) mostram que a participação de diversos setores com diversos níveis de poder (Estado, Comunidade, Organizações Não Governamentais e Bancos de Desenvolvimento) na implementação de programas de desenvolvimento têm maiores chances de sucesso, criando Capital Social através das interações dos participantes, sendo benéfico na hora de solucionar futuros problemas. 
Por último, FUKUYAMA (1999) faz uma classificação de como o Estado pode ser importante no estímulo do capital social na sociedade: a) o Estado deve estar atento para estimular alguma forma de aumentar o estoque de capital social já existente, como o apoio a programas de microcrédito, onde o índice de inadimplência é quase zero; b) o investimento e o estímulo na educação, pois é na escola que se formam futuros líderes e cidadãos. Esse estímulo não deve parar no ensino fundamental ou secundário, mas prosseguir até o ensino superior; c) fornecer bens públicos de forma eficiente e de qualidade, garantindo o direito à propriedade e segurança pública eficiente; d) descentralizar o Estado de forma a permitir um fluxo mais rápido e eficiente de serviços, permitindo também uma maior participação da sociedade na administração pública.

\section{3 - Material e Métodos}

\section{1 - Área Geográfica de Estudo}

As áreas geográficas de estudo são as comunidades de Sítio Lagoa e Lustal, município de Tauá que está localizado na região dos Inhamus, distante $337 \mathrm{Km}$ da capital, Fortaleza, e é uma das regiões mais secas do Ceará com precipitação média de $641 \mathrm{~mm}$, distribuídas em quatro meses do ano, com maior intensidade nos meses de março e abril, (VALE, 1999).

\section{2 - Procedimento Metodológico para Criação de Índice de Vulnerabilidade}

A criação do Índice de Vulnerabilidade baseia-se na metodologia ${ }^{3}$ para determinar o valor percebido pelo cliente por um produto no mercado, levando-se em consideração duas variáveis: preço e a qualidade percebida. No presente estudo elaborar-se-á um Índice de Vulnerabilidade considerando um elenco de variáveis representativas de capital social e capital físico para as comunidades de Lustal e Sítio Lagoa, no município de Tauá. Conhecer os anseios das comunidades a partir de seus problemas e potencialidades constitui para o tomador de decisão

\footnotetext{
${ }^{3}$ Para maior aprofundamento na metodologia ver: Gale (1996).
} 
- Capital Social, Capital Físico e a Vulnerabilidade do Sertanejo: o Caso das Comunidades de Lustal

e Sítio Lagoa no Município de Taua, Ceará

uma informação de grande relevância estratégica na construção de políticas de desenvolvimento com a participação ativa da comunidade.

Para a elaboração do Índice de Vulnerabilidade, levando em consideração o capital social e o capital físico, procedeu-se em duas etapas. Primeira etapa: a) elaborou-se um questionário contendo 26 variáveis representativas de capital social e sete variáveis representativas de capital físico, baseando-se na revisão de literatura e no conhecimento empírico da região. No caso das variáveis que compõem o capital físico utilizou-se, também, como critério, as características da região descritas a partir do conhecimento empírico da mesma, fortalecido por trabalhos como MAGALHÃES (1991) e SUASSUNA (2002) ; b) solicitou-se a seis especialistas ${ }^{4}$ no assunto reordenar estas variáveis de acordo com sua importância; e c) selecionaram-se as 10 variáveis com maior freqüência. Segunda etapa: d) selecionaram-se dez especialistas em Tauá, conhecedores das duas comunidades estudadas, Lustal e Sítio Lagoa. Solicitou-se a cada especialista que apresentasse uma ponderação de acordo com a importância relativa, tanto das variáveis de capital social como as de capital físico, para cada comunidade.

\section{3 - Definição das variáveis}

As 10 variáveis ${ }^{5}$ utilizadas na construção do Índice de Capital Social $\left(\mathrm{X}_{\mathrm{i}}\right)$ e as sete variáveis utilizadas na construção do Índice de Capital Físico $\left(\mathrm{Y}_{\mathrm{i}}\right)$ são descritas a seguir.

$\mathrm{X}_{1}=$ interações sociais, qualidade, quantidade e persistência das interações sociais através da igreja, clubes, escolas, vizinhos, amigos, membros de grupos e associações; e a habilidade de trabalho em conjunto para o bem comum.

\footnotetext{
${ }^{4} \mathrm{O}$ número de especialistas para o ordenamento das variáveis foi definido considerando a disponibilidade de pessoas com envolvimento, reconhecida experiência acadêmica e trabalhos publicados na área de capital social. Os especialistas no município foram selecionados devido a seus conhecimentos referentes às comunidades Lustal e Sítio Lagoa. ${ }^{5}$ A definição da forma de mensuração destas variáveis foi feita a partir de reuniões participativas com 16 comunidades heterogêneas, representativas do município, escolhidas por um conselho de conhecedores. Em todas as variáveis, atribuiu-se escore 1 para a situação mais desfavorável, 2 para a situação intermediária e 3 para a situação mais favorável.
} 
$\mathrm{X}_{2}=$ distribuição de renda.

$\mathrm{X}_{3}=$ tipo de status e poder dos indivíduos que formam as comunidades.

$\mathrm{X}_{4}=$ ambiente de confiança existente entre os membros da comunidade.

$\mathrm{X}_{5}=$ porcentagem de participantes por associação, dado o número de famílias existente na comunidade.

$\mathrm{X}_{6}=$ número de associações, clubes recreativos, grupos de jovens, entre outros.

$\mathrm{X}_{7}=$ número de escolas, tipo de instalações, postos de saúde, segurança, acesso a crédito, programas e projetos existentes.

$\mathrm{X}_{8}=$ diferenças referentes às interações da comunidade com instituições públicas e privadas.

$\mathrm{X}_{9}=$ fatos históricos da comunidade em que a solidariedade entre seus membros teve a sua mais alta expressão.

$\mathrm{X}_{10}=$ nível de escolaridade dos membros da comunidade.

$\mathrm{Y}_{1}=$ potencialidade produtiva da terra

$\mathrm{Y}_{2}=$ disponibilidade de água para consumo humano e do rebanho durante um ano de estiagem.

$\mathrm{Y}_{3}=$ tipo de acesso à comunidade em termos de rodovias intermunicipais.

$\mathrm{Y}_{4}=$ possibilidade de ter renda e emprego fora da comunidade, durante um ano de seca.

$\mathrm{Y}_{5}=$ tipo de tecnologia empregada na agropecuária (tradicional ou moderna).

$\mathrm{Y}_{6}=$ estrutura fundiária dominante na comunidade, proprietários ou não proprietários da terra onde trabalham.

$\mathrm{Y}_{7}=$ possibilidade de ter pequenas áreas irrigadas na comunidade, em períodos de estiagem.

É válido salientar que os procedimentos metodológicos utilizados obedecem, em grande parte, às bases estabelecidas no modelo conceitual do presente estudo. Entretanto, é importante reconhecer o grau de subjetividade tanto nas informações fornecidas pelos entrevistados como nos escores dados às variáveis utilizadas, o que seguramente se reflete na interpretação dos resultados. Porém, em se tratando de capital social, bem público intangível por natureza, acredita-se que a tentativa de mensurá-lo, de forma indireta, é um aparte à ciência. 
- Capital Social, Capital Físico e a Vulnerabilidade do Sertanejo: o Caso das Comunidades de Lustal e Sítio Lagoa no Município de Taua, Ceará

\section{4 - Resultados e Discussão}

Neste capítulo serão apresentados os resultados sobre as implicações do capital social e do capital físico na vulnerabilidade do homem do campo, o Índice de Vulnerabilidade, assim como as ações e prioridades encontradas para diminuir a vulnerabilidade da comunidade de Sítio Lagoa.

Na TABELA 1 constam os valores para encontrar o Índice de Capital Social - ICS e o Índice de Desenvolvimento do Capital Social - IDCS.

Tabela 1 - Ponderação das Variáveis, Escalas de Desempenho, Escores de Desempenho e o Índice de Capital Social e o Desempenho do Capital Social

\begin{tabular}{|c|c|c|c|c|c|c|}
\hline \multirow[t]{2}{*}{$\begin{array}{l}\text { Variáveis } \\
\text { (1) }\end{array}$} & \multirow{2}{*}{$\begin{array}{c}\text { Ponderação } \\
\text { (2) }\end{array}$} & \multicolumn{2}{|c|}{$\begin{array}{c}E^{I} \\
(3)\end{array}$} & \multirow{2}{*}{\begin{tabular}{|c|} 
EDCS $^{\text {II }}$ \\
$(4)$ \\
A/B \\
\end{tabular}} & \multirow{2}{*}{$\begin{array}{c}\begin{array}{c}\text { ICS }^{\text {III }} \\
(5)\end{array} \\
\Sigma\left[(2)^{*}(4)\right]\end{array}$} & \multirow{2}{*}{\begin{tabular}{|c}
$\begin{array}{c}\text { DCS }(\%)^{\mathrm{IV}} \\
(\mathbf{6})\end{array}$ \\
$\Sigma[(5)-(2)]^{*} 100$ \\
\end{tabular}} \\
\hline & & A (Lustal) & B (Sítio) & & & \\
\hline Interações sociais $\left(\mathrm{x}_{1}\right)$ & 0,15 & 8,50 & 4,12 & 2,06 & 0,31 & 16 \\
\hline Distribuição de renda $\left(\mathrm{x}_{2}\right)$ & 0,10 & 7,87 & 5,25 & 1,50 & 0,15 & 5 \\
\hline Associações, status e poder $\left(\mathrm{x}_{3}\right)$ & 0,15 & 7,75 & 7,12 & 1,09 & 0,16 & 1 \\
\hline Ambiente de confiança $\left(\mathrm{x}_{4}\right)$ & 0,10 & 8,50 & 5,38 & 1,58 & 0,16 & 6 \\
\hline Participantes por associação $\left(\mathrm{x}_{5}\right)$ & 0,10 & 8,75 & 4,37 & 2,00 & 0,20 & 10 \\
\hline Número de associações $\left(\mathrm{x}_{6}\right)$ & 0,05 & 8,25 & 4,00 & 2,06 & 0,10 & 5 \\
\hline Escolas, postos de saúde $\left(\mathrm{x}_{7}\right)$ & 0,10 & 8,37 & 3,50 & 2,39 & 0,24 & 14 \\
\hline Comunidade e instituições $\left(\mathrm{x}_{8}\right)$ & 0,10 & 8,50 & 4,25 & 2,00 & 0,20 & 10 \\
\hline Passado histórico $\left(\mathrm{x}_{9}\right)$ & 0,05 & 7,75 & 5,00 & 1,55 & 0,08 & 3 \\
\hline Nível de escolaridade $\mathrm{x}_{10}$ ) & 0,10 & 8,62 & 4,87 & 1,77 & 0,18 & 8 \\
\hline & 1,0 & $8,30^{\mathrm{V}}$ & $4,90^{\mathrm{VI}}$ & & 1,78 & 78 \\
\hline
\end{tabular}

Fonte: Dados da Pesquisa

I ED: Escala de Desempenho das comunidades A (Lustal) e B (Sítio Lagoa).

II EDCS: Escore de Desempenho do Capital Social.

III ICS: Índice de Capital Social.

Iv DCS: Desempenho do Capital Social.

$\checkmark \operatorname{DCSE}_{\mathrm{A}}$ : Desempenho do Capital Social Existente para a comunidade de Lustal $\Sigma[(2) *(\mathrm{~A})]$.

VI DCSE $_{\mathrm{B}}$ : Desempenho do Capital Social Existente para a comunidade Sítio Lagoa $\Sigma[(2) *(\mathrm{~B})]$.

As variáveis de capital social foram ponderadas, segundo a hierarquização dada pelos pesquisadores e especialistas na primeira fase, conforme mostrado na coluna 2 . 
Os valores da coluna 3 são as Escalas de Desempenho das comunidades $\underline{A}$ (Lustal) e $\underline{B}$ (Sítio Lagoa) atribuídas a cada variável da coluna 1 pelos especialistas na segunda fase. O somatório da multiplicação da ponderação (coluna 2) pela Escala de Desempenho da respectiva comunidade (coluna 3) resulta no Desempenho do Capital Social Existente para a respectiva comunidade $\left(\mathrm{DCSE}_{\mathrm{A}}\right.$, para a comunidade de Lustal, e $\operatorname{DCSE}_{\mathrm{B}}$ para a comunidade de Sítio Lagoa). Esse resultado representa uma média geral do capital social existente nas comunidades, sendo de 8,30 para Lustal e 4,90 para Sítio Lagoa. Esses valores refletem o melhor desempenho dos indicadores de capital social na comunidade de Lustal, comparando-a à de Sítio Lagoa.

Na coluna 4 são apresentados os Escores de Desempenho de Capital Social da comunidade Lustal, em relação a comunidade Sítio Lagoa que

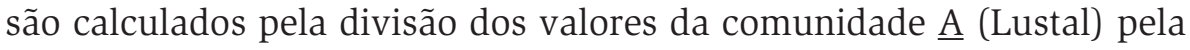
comunidade $\underline{B}$ (Sítio Lagoa), ou seja, A/B. Os valores acima de 1 indicam em que a comunidade de Lustal está melhor, comparando-a à comunidade de Sítio Lagoa.

A comunidade de Lustal destaca-se principalmente nas variáveis Interações sociais $\left(x_{1}\right)$; Participantes por associação $\left(x_{5}\right)$; Número de Associações $\left(x_{6}\right)$; Escolas, postos de saúde $\left(x_{7}\right)$ e Comunidade e instituições $\left(x_{8}\right)$. Esses resultados refletem a capacidade de organização e mobilização da comunidade de Lustal, comparando-a à de Sítio Lagoa. A prefeitura e a comunidade de Lustal têm uma intensa interação, que teve início em meados da década de 80, devido ao favorecimento geográfico da comunidade, permitindo a prática e implementação de projetos de irrigação, já que Lustal é favorecida pela passagem do Rio Trici e também por sua proximidade à Sede do município. Com o passar do tempo, a mobilização dentro da comunidade tornou-se fortalecida e hoje a comunidade de Lustal é conhecida por seu passado de luta, o que possibilitou uma significativa melhoria na qualidade de vida da comunidade. Já a comunidade de Sítio encontra-se praticamente isolada. Distante 60 quilômetros da Sede do município, a comunidade nunca foi estimulada a trabalhar em mutirão ou praticar qualquer outra forma de atividade que exigisse a cooperação dos seus membros. Esse resultado é confirmado quando recentemente a comunidade não conseguiu se or- 
Capital Social, Capital Físico e a Vulnerabilidade do Sertanejo: o Caso das Comunidades de Lustal e Sítio Lagoa no Município de Taua, Ceará

ganizar a tempo para reivindicar a instalação de energia elétrica através do projeto São José .

Na coluna 5 observa-se o Índice de Capital Social, que é calculado pelo somatório da multiplicação da ponderação (coluna 2) pelo Escore de Desempenho do Capital Social (coluna 4). O valor do índice de capital social 1,78 significa que a comunidade de Lustal tem $78 \%$ a mais de capital social que a comunidade de Sítio Lagoa.

Esses $78 \%$ estão divididos pelas 10 variáveis analisadas. Pode-se ver essa distribuição na coluna 6, que é o Desempenho do Capital Social calculado através do somatório da subtração do Índice de Capital Social (coluna 5) pela ponderação (coluna 2), multiplicado por 100. Observamos que na variável Interações sociais $\left(x_{1}\right)$, Lustal é superior a Sítio Lagoa em 16\%.

A TABELA 2 contém os valores atribuídos para calcular o Índice de Capital Físico e o Índice de Desenvolvimento do Capital Físico que, somado Ao Índice de Desenvolvimento do Capital Social, resultará no Índice de Vulnerabilidade.

Na interpretação de seus valores, procede-se de forma similar à tabela anterior. As variáveis de capital físico foram ponderadas pelos pesquisadores do Projeto Arizona ${ }^{7}$ mediante ajuste realizado pelos representantes das comunidades, conforme mostrado na coluna 2 .

Os valores da coluna 3 são as Escalas de Desempenho das comunidades A (Lustal) e B (Sítio Lagoa) atribuídos a cada variável da coluna 1. O somatório da multiplicação da ponderação (coluna 2) pela Escala de Desempenho da respectiva comunidade (coluna 3) resulta no Desempenho do Capital Físico Existente para a respectiva comunidade $\left(\mathrm{DCFE}_{\mathrm{A}}\right.$, para a

\footnotetext{
${ }^{6}$ O Projeto São José foi criado em 1995 pelo Governo do Estado do Ceará com o objetivo de implementação de ações de desenvolvimento sustentável no Estado com participação ativa das comunidades, visando aumentar o acesso destas às atividades de geração de emprego e renda, assim como a previsão de serviços sociais básicos e de infra-estrutura como meios para redução da pobreza rural.

7 O Projeto Arizona é um Convênio entre a Universidade Federal do Ceará e a Universidade do Arizona, financiado com recursos da National Oceanic and Atmospheric Administration (NOAA). A primeira etapa deste projeto consistiu em determinar e analisar as estratégias seguidas pelos agricultores quando uma seca é anunciada. Nesta etapa também foram analisadas as medidas tomadas para diminuir o impacto causado pela estiagem, no homem do campo. Na segunda parte do trabalho pretende-se elaborar um plano de convivência com o semi-árido no curto, médio e longo prazo.
} 
comunidade de Lustal, e $\mathrm{DCFE}_{\mathrm{B}}$ para a comunidade de Sítio Lagoa). Esse resultado representa uma média geral do capital físico existente nas comunidades, sendo de 7,64 para Lustal e 4,17 para Sítio Lagoa. Esses valores refletem o melhor desempenho dos indicadores de capital físico na comunidade de Lustal, comparando-a à de Sítio Lagoa.

Tabela 2 - Ponderação das Variáveis, Escalas de Desempenho, Escores de Desempenho, o Índice de Capital Físico e o Desempenho do Capital Físico

\begin{tabular}{|c|c|c|c|c|c|c|}
\hline \multirow[t]{2}{*}{$\begin{array}{l}\text { Variáveis } \\
\text { (1) }\end{array}$} & \multirow{2}{*}{$\begin{array}{c}\text { Ponderação } \\
\text { (2) }\end{array}$} & \multicolumn{2}{|c|}{$\begin{array}{l}E D^{I} \\
(3)\end{array}$} & \multirow{2}{*}{\begin{tabular}{|c|} 
EDCF $^{\text {II }}$ \\
$(4)$ \\
A/B
\end{tabular}} & \multirow{2}{*}{$\begin{array}{c}\text { ICF }^{\text {III }} \\
(5) \\
\Sigma\left[(2)^{*}(4)\right]\end{array}$} & \multirow{2}{*}{\begin{tabular}{|c} 
DCF $(\%)^{\mathrm{IV}}$ \\
$(\mathbf{6})$ \\
$\Sigma[(5)-(2)]^{*} 100$
\end{tabular}} \\
\hline & & A (Lustal) & B (Sítio) & & & \\
\hline Potencialidade produtiva $\left(\mathrm{y}_{1}\right)$ & 0,10 & 8,62 & 6,62 & 1,30 & 0,130 & 3,0 \\
\hline Água para consumo humano $\left(\mathrm{y}_{2}\right)$ & 0,25 & 7,75 & 4,12 & 1,88 & 0,470 & 22,0 \\
\hline Acesso $\left(y_{3}\right)$ & 0,10 & 9,00 & 3,75 & 2,40 & 0,240 & 14,0 \\
\hline Renda e emprego $\left(\mathrm{y}_{4}\right)$ & 0,25 & 6,87 & 3,75 & 1,83 & 0,457 & 20,8 \\
\hline Tecnologia $\left(\mathrm{y}_{5}\right)$ & 0,10 & 7,37 & 4,00 & 1,84 & 0,184 & 8,4 \\
\hline Estrutura fundiária $\left(\mathrm{y}_{6}\right)$ & 0,10 & 8,25 & 5,37 & 1,54 & 0,154 & 5,4 \\
\hline \multirow[t]{2}{*}{ Irrigação $\left(\mathrm{y}_{7}\right)$} & 0,10 & 6,62 & 2,25 & 2,94 & 0,294 & 19,4 \\
\hline & 1,0 & $7,64^{\mathrm{V}}$ & $4,17^{\mathrm{VI}}$ & & 1,93 & 93 \\
\hline
\end{tabular}

Fonte: Dados da Pesquisa.

I ED: Escala de Desempenho das comunidades A (Lustal) e B (Sítio Lagoa).

II EDCF: Escore de Desempenho do Capital Físico.

III ICF: Índice de Capital Físico.

IV DCF: Desempenho do Capital Físico.

$\mathrm{v} \mathrm{DCFE}_{\mathrm{A}}$ : Desempenho do Capital Físico Existente para a comunidade de Lustal $\Sigma[(2) *(\mathrm{~A})]$.

VI $\mathrm{DCFE}_{\mathrm{B}}$ : Desempenho do Capital Físico Existente para a comunidade de Sítio Lagoa $\Sigma[(2) *(\mathrm{~B})]$.

Na coluna 4 são apresentados os Escores de Desempenho de Capital Físico, que são calculados pela divisão dos valores da comunidade $\mathrm{A}$ (Lustal) pela comunidade B (Sítio Lagoa), ou seja, A/B. Os valores acima de 1 indicam em que a comunidade de Lustal está melhor comparando-a à comunidade de Sítio Lagoa. A comunidade de Lustal destacase nas variáveis: Humano $\left(y_{2}\right)$; Acesso $\left(y_{3}\right)$; Renda e emprego $\left(y_{4}\right)$; Tecnologia $\left(y_{5}\right)$ e Irrigação $\left(y_{7}\right)$.

Quanto ao Acesso $\left(y_{3}\right)$ a comunidade de Lustal encontra-se a apenas a 12 quilômetros da Sede do município, com estradas de boa qualidade, 
enquanto Sítio Lagoa está distante 60 quilômetros, com estradas precárias, levando muito tempo para se chegar à Sede do município. Essa distância se torna considerável em casos de urgência, como por exemplo, quando alguém adoece e precisa ser levado ao médico.

Quanto à Renda e emprego $\left(y_{4}\right)$, devido à intensa atividade agrícola, Lustal também tem uma grande demanda por mão-de-obra, principalmente na época em que se inicia o preparo da terra para o plantio. Às vezes a oferta de emprego é bem maior que a demanda, sendo necessário recorrer a comunidades vizinhas para contratar mão-de-obra. Em Sítio Lagoa ocorre o contrário: a demanda por mão-de-obra é bem maior do que a oferta. Em época de seca muita gente fica sem fazer nada, tendo como única fonte de sobrevivência a cesta básica fornecida pelo governo do Estado. Quanto à água para o consumo humano, a comunidade de Lustal possui várias fontes de água que raramente secam, como pequenos açudes, cacimbas e cacimbões. Em Sítio Lagoa a situação é precária, só existindo água quando chove no inverno "período de chuvas". Em época de seca a comunidade tem que ser abastecida por carro-pipa.

Quanto à Tecnologia $\left(y_{5}\right)$ a comunidade Lustal possui um trator que é de uso comum dos membros da associação comunitária. Já em Sítio Lagoa só se tem disponível a cultivadeira de tração animal.

Finalmente, quanto à irrigação $\left(y_{7}\right)$, a comunidade de Lustal apresenta várias áreas irrigadas devido ao Projeto de Irrigação iniciado junto com a ajuda da prefeitura, enquanto em Sítio Lagoa a agricultura depende da chuva que cai no período de março a maio.

Na coluna 5 o valor de 1,93 significa que a comunidade de Lustal tem $93 \%$ a mais de capital físico do que a comunidade de Sítio Lagoa.

Esses $83 \%$ estão divididos pelas sete variáveis analisadas. Podemos ver essa distribuição na coluna 6 que é o Desempenho do Capital Físico. Observamos que na variável Potencialidade produtiva $\left(y_{1}\right)$, Lustal é superior a Sítio Lagoa em 3\%, na variável gua para consumo humano $\left(y_{2}\right)$ em $22 \%$, Renda e emprego $\left(y_{4}\right)$ em 20,8\%, e Irrigação $\left(y_{7}\right)$ em 19,4\%.

\section{1 - Índice de Vulnerabilidade}

Os valores de, 0,60 atribuído ao Índice Relativo de Capital Social e 0,40 atribuído ao Índice Relativo de Capital Físico foram determinados 
mediante entrevista com os especialistas e estudiosos na área de capital social $^{8}$.

A multiplicação do Índice de Capital Social pelo Índice Relativo de Capital Social, que foi determinado em 0,60, dará como resultado o Índice de Desenvolvimento de Capital Social, que é de 1,068.

A multiplicação do Índice de Capital Físico pelo Índice Relativo de Capital Físico, que foi determinado em 0,40, dará como resultado o Índice de Desenvolvimento de Capital Físico, que é de 0,772.

Podemos agora calcular o Índice de Vulnerabilidade obtido mediante a seguinte a fórmula:

$I V=(I C S \times I R C S)+(I C F \times I R C F)$

onde:

$I V=(1,78 \times 0,60)+(1,93 \times 0,40)$

$I V=1,84$

onde:

ICS é o Índice de Capital Social; IRCS é o Índice Relativo de Capital Social; ICF é o Índice de Capital Físico e IRCF é o Índice Relativo de Capital Físico.

Esse resultado confirma que a comunidade de Lustal é $84 \%$ menos vulnerável aos impactos da seca do que a comunidade de Sítio Lagoa. A comunidade de Lustal apresentou melhores resultados em todas as variáveis analisadas, tanto de capital social quanto de capital físico.

\section{2 - Priorizando as Ações para Diminuir a Vulnerabilidade da Comunidade de Sítio Lagoa}

Na TABELA 3 apresentam-se as Diferenças de Desempenho entre as duas comunidades, assim como o Impacto e as Prioridades sugeridas de acordo com a metodologia de valor percebido pelo cliente para as variáveis de Capital Social ${ }^{9}$.

\footnotetext{
${ }^{8}$ Um maior peso foi dado ao capital social pois acredita-se que a formação e o fortalecimento do capital social de um território criam condições favoráveis para o desenvolvimento do capital produtivo e para a geração de novas oportunidades de trabalho e renda no âmbito local.

${ }^{9}$ Ver GALE, 1996.
} 
Capital Social, Capital Físico e a Vulnerabilidade do Sertanejo: o Caso das Comunidades de Lustal e Sítio Lagoa no Município de Taua, Ceará

Tabela 3 - Diferenças de Desempenho, Impacto e Prioridade das variáveis para capital social

\begin{tabular}{|c|c|c|c|c|c|c|}
\hline \multirow[t]{2}{*}{$\begin{array}{l}\text { Variáveis } \\
\text { (1) }\end{array}$} & \multirow[t]{2}{*}{$\begin{array}{c}\text { Ponderação } \\
\text { (2) }\end{array}$} & \multicolumn{2}{|c|}{$\begin{array}{c}E^{I} \\
(3)\end{array}$} & $\begin{array}{r}\mathrm{DD}^{\mathrm{II}} \\
(4) \\
\end{array}$ & $\begin{array}{c}\text { Impacto } \\
(5)\end{array}$ & \multirow{2}{*}{$\begin{array}{c}\text { Prioridade } \\
\text { (6) }\end{array}$} \\
\hline & & A (Lustal) & B (Sítio) & $(A-B)$ & {$[(2) *(4)] * 100$} & \\
\hline Interações sociais $\left(\mathrm{x}_{1}\right)$ & 0,15 & 8,50 & 4,12 & 4,38 & 65,70 & $1^{0}$ \\
\hline Distribuição de renda $\left(\mathrm{x}_{2}\right)$ & 0,10 & 7,87 & 5,25 & 2,62 & 26,20 & $7^{\circ}$ \\
\hline Associações, status e poder $\left(\mathrm{x}_{3}\right)$ & 0,15 & 7,75 & 7,12 & 0,63 & 9,45 & $10^{\circ}$ \\
\hline Ambiente de confiança $\left(\mathrm{x}_{4}\right)$ & 0,10 & 8,50 & 5,38 & 3,12 & 31,20 & $6^{\circ}$ \\
\hline Participantes por associação $\left(\mathrm{x}_{5}\right)$ & 0,10 & 8,75 & 4,37 & 4,38 & 43,80 & $3^{\circ}$ \\
\hline Número de associações $\left(\mathrm{x}_{6}\right)$ & 0,05 & 8,25 & 4,00 & 4,25 & 21,25 & $8^{\circ}$ \\
\hline Escolas, postos de saúde $\left(\mathrm{x}_{7}\right)$ & 0,10 & 8,37 & 3,50 & 4,87 & 48,70 & $2^{\circ}$ \\
\hline Comunidade e instituições $\left(\mathrm{x}_{8}\right)$ & 0,10 & 8,50 & 4,25 & 4,25 & 42,50 & $4^{\circ}$ \\
\hline Passado histórico $\left(\mathrm{x}_{9}\right)$ & 0,05 & 7,75 & 5,00 & 2,75 & 13,75 & $9^{\circ}$ \\
\hline Nível de escolaridade $\left(\mathrm{x}_{10}\right)$ & 0,10 & 8,62 & 4,87 & 3,75 & 37,50 & $5^{0}$ \\
\hline
\end{tabular}

Fonte: Dados da Pesquisa

I ED: Escala de Desempenho das comunidades A (Lustal) e B (Sítio Lagoa).

II DD: Diferença de Desempenho para as variáveis de capital social.

III Prioridade: quanto maior o valor do Impacto (coluna 5), maior será considerada a prioridade.

Os valores da ponderação apresentados na coluna 2 e os Escores de Desempenho apresentados na coluna 3, para cada variável de capital social, são os mesmos anteriormente apresentados na Tabela 1.

A partir da coluna 4 são apresentadas as Diferenças de Desempenho entre as comunidades. Existem diferenças expressivas em todas as variáveis analisadas com exceção da variável Associações, status e poder, que diz respeito às associações que congregam indivíduos do mesmo status e do mesmo poder, ou seja, se nas associações todos têm o mesmo status ou poder de decisão. Ambas as comunidades tiveram aproximadamente a mesma nota, sendo que na comunidade de Lustal suas associações são mais ativas do que a única associação existente em Sítio Lagoa.

Depois de verificadas as diferenças entre as comunidades, é possível calcular o Impacto, na coluna 5, que essas diferenças causam à comunidade de Sítio Lagoa, levando-se em consideração a ponderação atribuída a cada variável. O Impacto é calculado através da multiplicação da ponderação (coluna 2) pela Diferenças de Desempenho (coluna 4).

O resultado do Impacto irá estabelecer Prioridades das variáveis, 
visualizadas na coluna 6. Quanto maior o valor, maior o Impacto negativo na comunidade de Sítio Lagoa, sendo, assim, é possível estabelecer Prioridades para as variáveis. O que essa operação representa basicamente é que, quanto maior a Diferença de Desempenho e quanto maior a importância atribuída através da ponderação, maior será a Prioridade, no sentido de amenizar as Diferenças de Desempenho existentes entre as comunidades de Lustal e Sítio Lagoa, levando em consideração a sua importância atribuída.

As prioridades seguem na seguinte ordem: Interações sociais $\left(x_{1}\right)$, Escolas, postos de saúde $\left(x_{7}\right)$, Participantes por associação $\left(x_{5}\right)$, Comunidade e instituições $\left(x_{8}\right)$, Nivel de escolaridade $\left(x_{10}\right)$, Ambiente de confiança $\left(x_{4}\right)$, Distribuição de renda $\left(x_{2}\right)$, Número de associações $\left(x_{6}\right)$, Passado histórico $\left(x_{9}\right)$ e Associações, status e poder $\left(x_{3}\right)$.

Fica clara a maior interação dos membros da comunidade de Lustal quando comparada à comunidade de Sítio Lagoa. Nesse processo é evidente a importância do papel e maior presença da prefeitura municipal na comunidade de Lustal, comparando-se à de Sítio Lagoa, no sentido de incentivar e fomentar a persistência das interações sociais entre vizinhos, amigos, membros de grupos e associações, e a habilidade dos membros da comunidade em trabalharem juntos para o bem comum. Uma das formas em que a prefeitura vem desempenhando efetivamente este papel tem sido através dos Agentes Rurais, técnicos agrícolas responsáveis pelo acompanhamento do pequeno produtor rural, que se tornaram uma importante peça do planejamento municipal, já que adquiriram um profundo conhecimento das condições sociais, políticas e econômicas das comunidades pertencentes ao município de Tauá. Os Agentes Rurais servem como uma ponte entre comunidades e prefeitura, sendo muitas vezes a única fonte que as comunidades têm de reivindicar seus direitos frente à prefeitura municipal. Um exemplo disso é a distribuição estratégica dos carros-pipa em época de seca. O conhecimento que os Agentes Rurais têm sobre a realidade do município pesa significativamente na hora da alocação dos carros-pipa, tornando a distribuição da água mais eficiente e justa.

Na TABELA 4 apresentam-se as Diferenças de Desempenho entre as duas comunidades, assim como o Impacto e as Prioridades das variáveis de Capital Físico. 
Os valores da ponderação apresentados na coluna 2 e os Escores de Desempenho apresentados na coluna 3, para cada variável de capital físico, são os mesmos anteriormente apresentados na Tabela 2.

A partir da coluna 4 são apresentadas as Diferenças de Desempenho entre as comunidades. Existem diferenças expressivas entre as comunidades, principalmente nas variáveis Acesso $\left(y_{3}\right)$ e Irrigação $\left(y_{7}\right)$. Quanto ao Acesso $\left(y_{3}\right)$, Lustal está distante 12 quilômetros da Sede do município com estradas consideradas de boa qualidade, enquanto a distância de Sítio Lagoa até a Sede é de 60 quilômetros de estradas precárias, que ficam piores quando chove, tornando difícil o acesso à comunidade. Já quanto à Irrigação $\left(y_{7}\right)$, na comunidade de Lustal a sua prática é comum, mas diminuiu com a construção da adutora que abastece a Sede do município, enquanto que na comunidade de Sítio Lagoa não existe nenhuma forma de irrigação “só a água da chuva quando cai”, afirmou a Agente de Saúde da comunidade.

Tabela 4 - Diferenças de Desempenho, Impacto e Prioridade das ações para as variáveis de capital físico

\begin{tabular}{|c|c|c|c|c|c|c|}
\hline \multirow[t]{2}{*}{$\begin{array}{l}\text { Variáveis } \\
\text { (1) }\end{array}$} & \multirow{2}{*}{$\begin{array}{c}\text { Ponderação } \\
\text { (2) }\end{array}$} & \multicolumn{2}{|c|}{$\begin{array}{l}E^{I} \\
(3)\end{array}$} & \multirow{2}{*}{\begin{tabular}{|c|}
$\begin{array}{c}D^{I I} \\
(4)\end{array}$ \\
$(A-B)$ \\
\end{tabular}} & \multirow{2}{*}{\begin{tabular}{|c|} 
Impacto \\
$(5)$
\end{tabular}} & \multirow{2}{*}{$\begin{array}{c}\text { Prioridade }^{\mathrm{III}} \\
\text { (6) }\end{array}$} \\
\hline & & A (Lustal) & B (Sítio) & & & \\
\hline Potencialidade Produtiva $\left(\mathrm{y}_{1}\right)$ & 0,10 & 8,62 & 6,62 & 2,00 & 20,00 & $7^{\circ}$ \\
\hline Água para consumo humano $\left(\mathrm{y}_{2}\right)$ & 0,25 & 7,75 & 4,12 & 3,63 & 90,75 & $1^{0}$ \\
\hline Acesso $\left(y_{3}\right)$ & 0,10 & 9,00 & 3,75 & 5,25 & 52,50 & $3^{\circ}$ \\
\hline Renda e Emprego $\left(y_{4}\right)$ & 0,25 & 6,87 & 3,75 & 3,12 & 78,00 & $2^{\circ}$ \\
\hline Tecnologia $\left(\mathrm{y}_{5}\right)$ & 0,10 & 7,37 & 4,00 & 3,37 & 33,70 & $5^{\circ}$ \\
\hline Estrutura Fundiária $\left(\mathrm{y}_{6}\right)$ & 0,10 & 8,25 & 5,37 & 2,88 & 28,80 & $6^{0}$ \\
\hline Irrigação $\left(\mathrm{y}_{7}\right)$ & 0,10 & 6,62 & 2,25 & 4,37 & 43,70 & $4^{\circ}$ \\
\hline
\end{tabular}

Fonte: Dados da Pesquisa

I ED: Escala de Desempenho das comunidades A (Lustal) e B (Sítio Lagoa).

II DD: Diferença de Desempenho para as variáveis de capital físico.

II Prioridade: quanto maior o valor do Impacto (coluna 5), maior será considerada a prioridade.

Depois de verificadas as diferenças entre as comunidades é possível calcular o Impacto, na coluna 5, que elas causam à comunidade de Sítio Lagoa, levando-se em consideração a ponderação atribuída a cada vari- 
ável. O Impacto é calculado através da multiplicação da ponderação (coluna 2) pela Diferenças de Desempenho (coluna 4), e sua interpretação, bem como das prioridades de ação, é a mesma descrita na análise da Tabela 3.

As prioridades seguem na seguinte ordem: Água para consumo humano $\left(y_{2}\right)$, Renda e emprego $\left(y_{4}\right)$, Acesso $\left(y_{3}\right)$, Irrigação $\left(y_{7}\right)$, Tecnologia $\left(y_{5}\right)$, Estrutura fundiária $\left(y_{6}\right)$ e Potencialidade produtiva $\left(y_{1}\right)$.

A falta de água para consumo humano é um dos principais problemas enfrentados hoje pela comunidade de Sítio Lagoa. A construção de pequenos açudes, assim como a construção de cisternas de placa, são uma forma de conviver com a seca. Uma cisterna de placa de $15 \mathrm{mil}$ litros custa aproximadamente $\mathrm{R} \$ 400,00$ (quatrocentos reais), fornecendo água de boa qualidade para beber e cozinhar por oito meses a uma família de aproximadamente seis a sete pessoas, sendo apontada pela comunidade como possível solução para o problema da falta de água para o consumo humano na região.

Essa pratica, além de ser economicamente mais viável do que o uso de dessalinizadores, garante a boa qualidade da água. A prefeitura municipal atualmente tenta resolver o problema através da perfuração de poços profundos nas áreas consideradas críticas. Essa prática tem tido alguns resultados positivos, porém em alguns poços perfurados o nível de salinidade tem sido muito elevado, sendo necessário o uso de dessalinizadores. A constante manutenção necessária vem elevando consideravelmente os custos para a prefeitura.

\section{5 - Conclusões e Sugestões}

A primeira conclusão que se pode oferecer a partir do presente trabalho é sobre a relevância do capital social como diferencial essencial no nível de vulnerabilidade existente nas comunidades de Lustal e Sítio Lagoa. A comunidade de Lustal aparece mais bem dotada de capital social e capital físico e, portanto, é menos vulnerável que a comunidade de Sítio Lagoa. Em termos de capital físico merecem destaque as variáveis Emprego e Renda e vias de Acesso da comunidade à Sede municipal. Mas, especial atenção deve ser dada à Água para consumo humano, pois é uma variável crítica que determina o comportamento das 
outras variáveis componentes do capital físico. A convivência com o semi-árido surge de uma nova postura cultural de afinidade com a natureza e especialmente com a água.

A segunda conclusão refere-se à importância relativa dos sistemas de participação cívica, como a Igreja, clubes e escolas na formação de capital social. Observam-se também na comunidade, as escolas, postos de saúde, programas, projetos e acesso a crédito como parte relevante na formação de capital social. Não menos importante é o número de participantes por associação e o relacionamento e entrosamento entre a comunidade e as instituições públicas e privadas na formação de capital social. A melhor performance destas variáveis na comunidade de Lustal, quando comparada com Sítio Lagoa, determinam, pelo menos em parte, o resultado do Índice de Vulnerabilidade encontrado.

A terceira conclusão refere-se à existência de diferenças de desempenho das variáveis de capital social e capital físico na comunidade de Lustal que a fazem menos vulnerável que a comunidade de Sítio Lagoa.

Recomenda-se o fomento às autoridades, de atividades que venham a alavancar a formação ou crescimento do capital social nas comunidades. Talvez seja a peça chave que permitirá às comunidades diminuir a vulnerabilidade e enfrentar os impactos da seca e a distribuição inadequada de recursos e serviços. Deve-se fomentar o desenvolvimento endógeno, ou seja, incentivar as iniciativas que, partindo da comunidade, visem à melhoria da coletividade. Sendo a educação o elemento intangível que está presente na estrutura de todas as variáveis determinantes do surgimento ou crescimento do capital social, na comunidade, deve-se fomentar a educação formal e informal, cursos técnicos através do Centro Vocacional Tecnológico (CVT), do Centro de Ensino Tecnológico (CENTEC), mini-cursos nas áreas de manejo dos recursos hídricos, previsões de tempo e clima, agronomia e zootecnia entre outros.

\section{Referências Bibliográficas}

BOLE, Hans G. et al. Climate change and social vulnerability: toward a sociology and geography of food insecurity. [s.l.], Global Environmental Change. v.4, n.1, p. $37-48,1994$. 
BROWN, L David and ASHMAN, Darcy. Participation, social capital, and intersectoral problem solving: african asian cases. [s.l.], World Development. v.24, n.9, p. 1467 - 1479, 1996.

CATTELL, Vicky. Poor people, poor places and poor health: The mediating role of social networks and social capital. [s.l.], Social Science and Medicine. v.52, p. $1501-1516,2001$.

COLEMAN, James S. Social capital in the creation of human capital. [s.l.], American Journal of Sociology. v.94(supplement), p. 95-120, 1998.

FUKUYAMA, Francis. Social capital and the global economy. [s.l.], Foreign Affairs. v.74, n.5, p. 89-99, 1995.

FUKUYAMA, Francis. Social capital and civil society. Prepared for the International Monetary Fund Conference on Second Generation Reforms, 1999. Disponível em < http://www.imf.org/external/pubs/ft/seminar/1999/reforms/ fukuyama.htmI.1999 > Acesso em Mar. 2002.

FUNCEME. Curso de informações básicas sobre meteorologia. 1998. 49p. Disponível em: < http//:www.funceme.br.fortaleza > Acesso em Mar. 2002.

GALE, Bradley T. Gerenciando o valor do cliente: Criando qualidade \& serviços que os clientes podem ver. São Paulo: Pioneira, 1996, 368p.

GRANOVETTER, Mark S. Economic action and social structure: the problem of embeddedness. [s.l.], American Journal of Sociology. v.91, n.3, p. 481-510, 1985.

1973. The Strength of weak ties. [s.l.] American Journal of Sociology. v.78, n.6, p. 1361 - 1380, 1973.

JARA, Carlos J. Capital social e desenvolvimento local sustentável. Equador: Instituto Interamericano de Cooperação para a Agricultura, 1999, 29p.

KELLY, P. e ADGER, W. Theory and practice in assessing vulnerability to climate change and facilitating adaptation. Netherlands: Klumer Academic Publishers, v.47, p. $325-352,2000$.

MAGALHÃES, A. Respostas governamentais às secas: a experiência de 1987 no Nordeste. Fortaleza. Imprensa Oficial do Ceará, 1991. 231p.

MONASTÉRIO, Leonardo M. Capital social e grupos de interesse. Uma reflexão 
no âmbito da economia regional. In: ENCONTRO DA ASSOCIAÇÃO NACIONAL DE PÓS-GRADUAÇÃO EM ECONOMIA - ANPEC, 27,1999, Belém. Disponível em < http://www.capitalsocial.cjb.net > Acesso em mar. 2000.

PROJETO ARIZONA. Uso e utilidade: um estudo comparativo dos sistemas de previsão climática em regiões da América Latina afetadas pela seca. Parceria Brasil e Estados Unidos, 2002, 51p.

PUTNAM, R. D. Comunidade e democracia: a experiência da Itália moderna. 2.ed. Rio de Janeiro: FGV, 2000.

SUASSUNA, J. Semi-árido: Proposta de convivência com a seca. Fortaleza. Fundação Konrad Adenauer. 2002. 13p.

VALE, Ana Moreira. Descobrindo e construindo Tauá: conhecimentos de geografia e história. Fortaleza: Fundação Demócrito Rocha, 1999, 120p.

WORLD BANK. Conceitos disponíveis no site do Banco Mundial. Disponível em < http://www.worldbank.org/poverty/s.capital > Acesso em mar. 2002.

Recebido em março de 2003 e revisto em agosto de 2003. 